\title{
O ART 1.777 DO CODIGO CIVIL
}

$\mathrm{Na}$ interpretação desse artigo, os nossos juizes se agrupam em duas correntes:

- uma - a dos que dispensam a concordancia de todos os interessados, para a adjudicação requerida por um ou mais herdeiros, só mandando o immovel a praça quando não haja motivo de preferencia entre dois ou mais interessados que disputam a adjudicação, ou quando nenhum a requer;

- outra - a dos que exigem a concordancia de todos os interessados, entendendo que assim applicam, ao art. 1777, a regra do art. 632 do Codigo.

A primeira corrente é representada por numerosos julgados, como se vê na Revista dos Tribunaes, 45/379, 51/443, 55/395, 58/471, Revista forense, 29/166, 50/109. Revista de Direito, 59/351.

Essa corrente tem por si a autoridade de Clovis BevILAQUA (1) e JoÃo LUIS AlveS, que assim se manifestaram em seus commentarios. "A providencia consignada no art. 1777, diz o primeiro, é um modo adequado de solver uma difficuldade. Em primeiro logar, a providencia referefere se exclusivamente aos immoveis; depois, o recurso da hasta publica só se verifica se algum dos coherdeiros não requrer que the seja adjudicado o bem, repondo aos outros, em dinheiro, o que exceder do seu quinhão. A razão da

(1) - De Clovis, no Cod. civ., comm. ao art. 1777, pois nas Soluções pratica de direito p. 497, subordina a adjudicação á acquiescencia dos demais herdeiros, applicando a regra do art. 632 e admittindo, assim, a venda forçadxa, porém não a forçada adjudicą̧ão. 
preferencia... O Codigo deixou a solução desta difficuldade ao criterio do juiz, e este decidir-se-á attendendo ás circumstancias particulares do caso, á situação do immovel, á sua melhor exploração, ás bemfeitorias, e á prioridade" Escreve o segundo: "A providencia é restricta á coisa immovel e para que a venda se realize, em hasta publica, é preciso: $\left.1 .^{\circ}\right)$ que a coisa não se preste a commoda divisão, pois que, sendo esta possivel, deve-se partilhar aos herdeiros; $2 .^{\circ}$ ) que não caiba no quinhão de um herdeiro, caso em que, como no Dir. Ant., se lhe deve adjudical-a, $3 .^{\circ}$ ) que nenhum herdeiro requeira a adjudicaçẫo pelo valor do inventario, repondo aos outros o que exceder do seu quinhão. Verificadas essas condições, o recurso unico será a venda do immovel em hasta publica, para ser partilhado o preço, desde que o estado de communhão forçada é repellido pelo direito"

A segunda corrente é representada por poucos julgados: Rev. dos Trib., 68/52.

Em nosso Tribunal, a 2. ${ }^{2}$ Camara, unanimemente, segue a primeira corrente; e a $1 . .^{\text {a }}$, contra os votos discordantes dos eminentes ministros Julio DE FARIA e AFFonso DE Carvalho, filiou-se á segunda corrente. Quer isso dizer que, em Camaras reunidas, será mantida - como já foi em um caso - a fórma pela qual tem decidido a $2{ }^{a} \mathrm{Ca}$ mara. E é essa, a nosso ver, a verdadeira doutrina.

Em um caso que levámos ao Tribunal (Revista dos Tribunaes, 50/443), foram votos vencidos os srs JULIO DE FaRIa e COSTa Manso. O primeiro, porém, por outros motivos e não por julgar que 0 art. 1777 se devesse interpretar pelo 632, tanto que anteriormente votara no mesmo sentido da interpretação que defendemos (Revista dos Tribunaes, 45/379).. O sr. Costa Mansó justificou o seu voto vencido advogando a interpretação do art. 1777 pelo 632, baseado em Menezes, Pinto de Toledo e RAMALHO. 
O accordam que vem na Revista dos Tribunaes, 68/52, relatado pelo illustre ministro AnTONINo VIEIRA, diz, citando a PINTO DE TOLEDO, que em nosso direito anterior, "quando os bens não admittiam commoda divisão, ou eram lançados no quinhão de um só herdeiro, havendo accordo dos demais, ou vendidos em hasta publica, dividindo-se o producto", e conclue entendendo que o art. 1777 deve ser interpretado "de accordo com o disposto no artigo 632"

Analysemos, porem, os fundamentos em que se baseia a segunda corrente, e veremos que não resistem á critica.

Em seu mencionado voto vencido, diz o sr. Costa MANSO: "Requerida a adjudicação, será o pedido processado segundo as leis formaes e as praxes, e estas exigem audiencia dos co-herdeiros, só se deferindo a adjudicação quando haja unanime consenso: vide - PINTO DE TOLEDO, "Processo orphanologico, $\$ \$ 422,454$, arts. 115 e 538; RANALHO, Instituições orphanologicas, $\S 126$, n. ${ }^{\circ}$ II e 116; MeneZES, Juizos divisorios, parte I, cap. II $\$$ XXXI, cap. III, $\S \S \S$ VII, XII, etc." - Vejamos si essas autoridades suffragam a opinião do eminente Juiz.

De Menezes, a parte I, cap. II $₫ X X X I$, trata de adjudicação de bens a credor da herança; o cap. III, § VII, idem, resta o \$XII deste capitulo, o unico applicavel á especie e que diz justamente o contrario do que se pretende, pois delle consta que as propriedades urbanas, ou rusticas, que não têm commoda divisão, devem ser lançadas inteiras a cada herdeiro, ou ser adjudicada a um daquelles que mais votos tiver, em o valor que os louvados tiverem estimado"

De Pinto DE Toledo, Proc. orphanologico, o $₫ 422$ se refere á adjudicação a credor da herança; o $\$ 454$ diz que ha licitação em os bens que cabem no quinhão de herdeiro, ou não comportam divisão commoda. Resta o $\ 538$, que diz effectivamente: - "Si os herdeiros não concordarem com a adjudicação, mandará o Juiz que sejam esses bens vendidos em hasta publica" Cita o autor, porém, a RAMALHO, Instituições orphanologicas, $\ 126$ e nota 893, de 
onde tirou o seu artigo. A verificação das palavras deste nunca assás louvado praxista, portanto, esclarecerá o pensamento de PINTO DE TOLEDO, e mostrará que este egregio autor e juiz não exige a concordancia de todos os interessados, nas adjudicações.

RAMALHO é tambem citado no voto vencido, no mesmo passo. Por isso, vamos transcrever-lhe as palavras: "As que comportão uma divisão, mas que sendo partidas, perdem o seu valor... Tambem estas cousas se não dividem, mas adjudicão-se á um dos herdeiros com a obrigação de satisfazer aos outros o que lhes cabe no valor, e se não concordão neste alvitre... Mas se concordão os herdeiros na adjudicação, e aquelle á quem foi adjudicada não tem meios..." (Note-se que não é este 0 caso: bens que comportam divisão, mas que, sendo partidos, perdem o seu valor. Para esses é qué se exige o consentimento dos herdeiros, quando os bens são divisiveis). O caso de indivisibilidade se encontra em a nota 893 , na qual diz unicamente: "As propriedades, que não se prestão á uma divisão commoda, adjudicão-se inteiramente á um dos herdeiros", disposição que, figurando como nota ao texto, na parte em que fala das que comportam divisão, vale como excepção á regra alli estabelecida.

Assim, os autores invocados pelo voto vencido dizem o contrario do que se lhes attribuiu.

Esboroados os fundamentos que invocam para applicação, no juizo familiæ erciscundæ, da regra que rege o condominio, resta ver si ella subsiste, em face da regras da hermeneutica e dos principios geraes de direito.

Quanto ao primeiro ponto, deve observar-se que se não admittem palavras superfluas na lei, e que a interpretação do artigo 1.777 pelo 632 faria suppôr não apenas palavras superfluas, mas um artigo superfluo. Com effeito, si a regra a observar-se é, mesmo no juizo familiæ erciscundæ, a do art. 632, o art. 177 será uma inutilidade na systematica do Codigo, será um kysto, uma excrescencia. Que 
disporia o art. 1777, no entender da segunda corrente? Que o immovel irá á praça, não havendo concordancia de todos os interessados, para que a adjudicação se faça a um só. Que dispõe o art. 632? - A mesma cousa. Não ha nenhuma subtileza que consiga encontrar qualquer outra regrinha para justificar a existencia do art. 1777

Ainda mais: o Codigo estabelece, no art. 641: - "Applicam-se, nos casos omissos, á divisão do condominio, as regras de partilha da herança" Como pode a segunda corrente explicar não haver, entre os dispositivos sobre a partilha, uma regra estabelecendo que serão subsidiarias as que regulam o condominio?

Mais não era preciso dizer para defender a opinião da primeira corrente. Não deixemos, porém, pedra sobre pedra.

Será a interpretação da primeira corrente contraria aos principios geraes de direito?

Vejamos a solução no direito comparado e em nosso direito anterior.

Digamos desde logo que a segunda corrente tem a seu favor um argumento que ainda não vimos invocado: é que a regra do Codigo espanhol, no art. 1062 (correspondente ao art. 632 de nosso Codigo) é geralmente seguida pelos Codigos americanos (Bolivia, art. 651; Uruguay, art. 1137; Chile, art. 1337; Venezuela, art. 1065) e mesmo europeus)

Diz o art. 1062 do Codigo espanhol: "Cuando una cosa sea indivisible ó desmerezca mucho por su división, podrá adjudicarse á uno, á calidad de abonar á los otros el exceso en dinero. Pero bastará que uno sólo de los herederos pida su venta en pública subasta, y con admisión de licitadores extraños, para que asi se haga"

O Codigo francês, art. 827 , nem cogita de adjudicação: prescreve logo o licitação: "Si les immeubles ne peuvent pas se partager commodément, il doit être procédé à la vente par licitation devant le tribunal. Cependant les parties, si elles sont toutes majeures, peuvent consentir que 
la licitation soit faite devant un notaire, par le choix duquel elles s'accordent" E' mais ou menos a solução do Codigo allemão, art. 753: "Quando a partilha em natureza não pode ser praticada, a cessação da indivisão tem logar pela venda do objecto indiviso de accordo com as prescripções sobre a venda de penhores - si se trata de immoveis pela venda em hasta - e pela distribuição do producto. $\mathrm{Si}$ a venda a um terceiro não é admissivel, o objecto deve ser licitado entre os condominos" No caso de condominio, manda que se venda no caso "qu'aucun des copartageants ne puisse ou ne veuille prendre" (art. 1686-1688)

O Codigo suisso não differe do espanhol sinão em que, pedida a venda em hasta, o juiz resolverá si deva ser publica ou apenas entre os coherdeiros.

O Codigo argentino estabelece o direito de licitar, excepto quando os herdeiros nada oppuzeram á avaliação e a partilha se faz pelo valor dos bens (art. 3467). No caso de condominio em predio indivisivel, prescreve a venda (art. 1324, n. $\left..^{\circ} .^{\circ}\right)$

E' de notar, comtudo, que a necessidade e conveninencia da adjudicação foi reconhecida em diversos codigos, sendo alguns expressos apenas com relação ás explorações agricolas, industriaes ou fabris, e estabelecendo outros regras para adjudicação de quaesquer immoveis.

Do primeiro typo é o Codigo espanhol, que no art. 1056 , in fine, permitte que o pae disponha no sentido de ser a propriedade agricola, industrial ou fabril, adjudicada a um dos herdeiros, satisfazendo em metallico a legitima dos demais herdeiros. O Codigo suisso erigiu essa faculdade em regra, attendendo a que o facto de o testador ter conservado o immovel agricola é, na grande maioria dos casos, prova do interesse que vê na conservação do mesmo, deixando muitos de manifestar esse interesse por falta de conhecimentos, e considerando não ser justo que uma propriedade que foi o fundamento da fortuna éá qual está ligado, quasi sempre, tambem o valor de affeição, passe a 
estranhos. Com effeito, assim dispõe o art. 620 desse Codigo: "S'il éxiste parmi les biens une exploitation agricole, elle est, en tant qu'elle constitue une unité économique, attribuée entièrement à celui des héritiers qui le demande et qui paraît capable de se charger de l'entreprise; le prix en est fixé à valeur de rendement. Cet héritier peut exiger que le bétail, le matériel et les approvisionnements servant à l'exploitation lui soient également attribués. Le prix d'attribution est fixé pour le tout selon les règles applicables à l'estimation des immeubles" No caso de opposição, fica ao criterio do juiz, que se regulará pelos usos locaes ou pela situação pessoal dos herdeiros (art. 621) O mesmo acontece com relação a uma industria que fórma accessorio da propriedade agricola: adjudica-se ao que a pede, e, em caso de opposição, resolve o juiz (art. 625).

Não precisará o coherdeiro, dest'arte, dizer, como MELIBEU :

Impius hæc tam culta novalia miles habebit!

Barbarus has segetes! En quo discordia cives

Perduxit miseros! En queis consevimus agros! trario

E não só precisará dizer essas palavras, mas ao con-

Fortunate senex! ergo tua rura manebunt!

Fortunate senex! hic, inter flumina nota

Et fontes sacros, frigus captabis opacum!

A regra da licitação, ou da hasta publica, para o immovel indivisivel, tem mesmo sido reconhecida inconveniente: - "Beaucoup d'excellents esprits, dizem Colin ET Capitant, Droit civil, vol. $3 .^{\circ}$ p. 525 , regrettent qu'il ne soit pas possible, dans ce cas, d'en assurer la transmission intégrale à l'un des cohéritiers, celui qui paraîtra le plus indiqué pour continuer l'œuvre interrompue du défunt et la tradition de la famille, sauf à donner satisfacion aux autres au moyen de soultes en rentes ou en capital" Accrescentam estes autores que esse dosideratum foi colli- 
mado pela legislação especial relativa á pequena propriedade (L. de 5 de Dezembro de 1922), que manda, em caso de conflicto de pretensões, ser feita a adjudicação ao coherdeiro designado pelo finado, e, na falta, ao conjuge sobrevivente. Entre os coherdeiros, na falta de designação pelo finado, a adjudicação é feita ao que mais votos tiver, e, na falta de maioria, pela sorte.

A lei das Sete Partidas manda vender predio indivisivel em herança apenas "caso que ninguno de los coproprietarios quiere ó pude admitir por entero" (art. 1755) No art. seg. dá a cada um dos proprietarios o direito de requerer a hasta publica, mas diz que assim se fará apenas no caso de haver coproprietario ausente, pessôa juridica ou menor.

O Codigo português, art. 2138, estabelece que haverá licitação, si não houver algum coherdeiro que no predio indivisivel tenha a maior parte ou que nelle necessariamente haja de ser encabeçado. E no art. 2145 que, não tendo havido licitação, os interessados deliberarão si o predio ha de ser vendido, adjudicado ou usofruido em commum.

$\mathrm{Na}$ Suecia, pela lei de 19 de Maio de 1845, na partilha, o immovel indivisivel cabe ao herdeiro que nelle tiver a parte maior, e, no caso de partes iguaes, ao irmão.

O Codigo da Russia sovietica, no art. 417, estabelece 0 resgate no caso de indivisão ou de partilha incommoda on desvantajosa.

E em nosso dir. ant?

Vejamos a solução desde o D. R.

No direito romano, a solução se encontra no fr. $55 \mathrm{D}$ (10-2) : Si familiæ erciscundæ, vel communi dividundo judicium agatur, et divisio tam difficilis sit ut pene impossibilis esse videatur, potest Judex in unius personam totam condemnationem conferre, et adjudicare omnes res. Esse fragmento, porém, deve ser entendido de accôrdo com o 22 
$\$ 1$ 1. t.: Familix erciscundæ judex potest pluribus eandem rem adjudicare, si aut pluribus fuerit unius rei præceptio relicta (ubi etiam necessitatem facere Pomponius scribit, ut pluribus adjudicetur) vel si certam partem unicuique coheredum adsignet; SED POTEST ETIAM, LICITATIONE ADMISSA, UNIREM ADJUDICARE.

No primeiro fragmento se vê que a regra era a mesma para a juizo familix erciscundæ e communi dividundo. No segundo se verifica que naquelle juizo a adjudicação se fazia licitatione admissa. E na lei n. ${ }^{\circ} 1$ do C. (3-37) se vê que do mesmo modo se procedia no juizo communi dividundo, a que se refere o titulo: Frater tuus si solam portionem prædii ad se pertinentem distraxit, venditionem revocari non oportet; sed adversus eum cum quo tibi idem prædium commune esse cœpit, communi dividundo judicio consiste: et ea actione universum prædium. SI LICITATIONE VICERIS, EXSOLUTA SOCIO PARTE PRETII OBTINEBIS: AUT PRETII PORTIONEM, SI MELIOREM OBTULERIT, CONSEQUERIS QUOD SI DIVISIO PRADII SINE CUJUSQUAM INJURIA COMMODE FIERI POTUERIT, PORTIONEM SUIS FINIBUS TIBI ADJUDICATAM POSSIDEBIS. E no fr. 3 h. t. regula a admissão de estranhos, á licitação: NONNUNQUAM ETIAM EXTRANEO EMPTORE ADMISSO, MAXIME_SI SE NON_SUFFICERE AD JUSTA PRETIA ALTER EX SOCIIS_SUA PECUNIA VINCERE VILIUS LICITANTEM PROFITEATUR.

Desse direito, passou a prática de licitação para o nosso antiga direito, no qual se introduziram temperamentos á regra, entre os quaes o de se não admittir sinão mediante consenso de todos e o de não prmittir licitação além do importe do quinhão do herdeiro. (Menezes, Prática dos inventarios, p. 82), além de que "o Juiz admitte os lanços dos herdeiros em termos habeis, mas quando faz a partilha não se governa pelo maior lanço sómente" (p. 87). E quando não é possivel o consentimento de todos para a licitação, tunc ad locationem illius rei procedendum est Pedro Barbosa, L. Non amplius, 26) 
Essa prática da licitação não decorreu de nenhum texto legal, mas do parecer de VALASCO, de quem salienta LOBÃO as "variedades e inconstancias", já oppondo-se á licitação, quer seja á cousa divisivel quer indivisivel, já admittindo-a, tambem indistinctamente, ora admittindo-a apenas para as cousas indivisiveis, ora relegando-a "para o ultimo remedio de se não conformarem os herdeiros em alguma das providencias da $\operatorname{Ord}$. L. 4 , t. $96, \llbracket 5$, vindo a assentar que no nosso reino só vem a ser praticavel n'este caso" (Supplemento ás acções summarias, p. 132)

Esta ordenação contém a regra a seguir no caso de cousas indivisiveis: "Tendo os herdeiros, ou companheiros alguma cousa, que não possão entre si partir sem damno, assi como escravo, besta, moinho, lagar, ou outra cousa semelhante, não a devem partir, mas devem-na vender a cada hum delles, ou a outra algum, qual mais quizerem, ou per seu aprazimento trocarão com outras cousas, se as hi houver. E se se não podérem por esta maneira avir, arrendalo-hão, e partirão a renda entre si"

O maior lanço a que se refere MENEZES, no trecho citado, serve apenas de base para o sorteio, como diz COELHO DA Rocha, Dir civil, $2 .^{\circ}$ vol., p. 66, ou para as adjudicações, que o juiz faz a seu arbitrio, attendendo á conveniencia de cada um, "como lhe parecer justo, igual e sem lesão", exercendo aquella faculdade que se refere a lei $3 .^{2}$ do Cod. de communi dividundo. Assim, a licitação tinha por fim principal estabelecer o justo valor da cousa, corrigindo os erros das avaliações. Essa é: tambem a conclusão a que se chega pela B. 11, de VALASCO, de Part., segundo a qual apenas se admitte a licitação quando alter ex hæredibus voluerit rem sibi adjudicari vili pretio respectu justi valoris et non aliter, doutrina que é tambem defendida por Franch: Debet dictis in casibus ad licitationem deveniri, quando is qui rem commune habet, non vult solvere pretium justum, quia si vult licitatio non est admittenda (Decis. 54, n. ${ }^{\circ} 13$ ) 
Eis ahi os remedios do antigo direito:

$\left.1 .{ }^{\circ}\right)$ a licitação, quando não houvesse aprazimento dos interessados para a adjudicação e houvesse para a licitação;

$\left.2 .^{\circ}\right)$ o arrendamento e partilha da renda, quando não houvesse aprazimento para a licitação.

Sobre essa pratica, convem fixar os seguintes pontos:

a) a licitação não é venda em hasta publica, pelo que se não admittem estranhos, excepto quando a cousa não couber no quinhão de nenhum dos coherdeiros e nenhum delles. a quizer (1);

b) licitação ha para corrigir a má avaliação "quando na herança haja uma cousa physicamente indivisivel, e todos os herdeiros tenham nella igual porção e cada um delles a queira (L. I. C. de com divid.) Se um tiver maior porção, deverá adjudicar-se a este pelo seu justo valor (L. $34 \$ 2 .^{\circ}$ cod. de donat. Lauterbach liv. $10 \mathrm{~T} 3 \$ 15$, e BACKMERS, De act., secc. 2 cap. $8 \S 39) ;(2)$.

c) não sendo possivel a adjudicação nem a licitação, por falta de aprazimento dos coherdeiros, a cousa não é vendida em hasta para se partilhar o preço, e sim arrendada, para se partilhar a renda.

Do ensinamento de Menezes - de que se deve fazer a adjudicação a um daquelles que mais votos tiver, em o valor que os louvados tiverem estimado, se vê que foi extendida aos immoveis indivisiveis aquella regra que as $\mathrm{Ord}$. estabeleciam para os fôros e aforamentos perpetuos (L. IV, Tit. $36, \S 1 .^{\circ}$ e Tit. $91, \S 23$ ), donde se conclui, que a licitação se fazia apenas quando todos os herdeiros pediam a adjudicação ut singuli. Effectivamente, no caso de a controversia ser apenas entre alguns herdeiros, os outros podem ser chamados a opinar sobre os motivos de preferencia que cada um apresentar, v. g., ter um coherdeiro a maior parte num predio, ter predio comtiguo, ter a mesma profissão do pae, etc.

(1) - Correa Telles (Dig. port., vol. 2, rt. 1101) exceptua o caso de haver menores, em que admitte estranhos independente do aprazimento dos coherdeiros.

(2) -.. Cormea Telles, Doutr. das acções, § 149 e nota. 
O estatuto de Eugubio, citado por Lobãó ( $A c c$. summ. p. 135 do supplemento), mandava que a controversia fosse dirimida pela sorte - Constito Judici de communione, si res divisionem patiatur, pronuntiare debet divisioni locum esse... Si vero rei communis commodam divisionem non patiatur, Judex mandet poni Partitum de Re et Pretio et si Partes dissentiant, Quæstio sorte dirimatur.

Esse processo de tirar á sorte ou de pôr em votação, não era desconhecido no Direito Romano, pois no fr. $5 \mathrm{D}$ (10-2) se aventa a hypothese de haver documentos hereditarios de interesse, no qual todos os herdeiros têm igual parte: si não estiverem de accôrdo sobre quem os deva guardar, sortiri e os oportet; aut ex consensu ut suffragio eligendus est amicus, apud quem deponantur. No direito francês (Colin et CapiTant, Droit civil, p. 523) e no português (Silva Carvalho, Manual de inventario, p. 336), formados os quinhões, são elles tirados á sorte. (1).

Não é recommendavel esse processo. Preferivel é á cegueira da sorte substituir o arbitrio esclarecido do juiz.

$$
* *
$$

Contra a licitação, vozes se levantaram no dir. ant., com argumentos taes que essa prática foi soffrendo restricções cada vez maiores, até que veiu o nosso Codigo civil, abolindo-a. Eis as palavras do autor do Codigo: "Não admitte o Codigo Civil a licitação... e, muito menos, a licitação de quaesquer bens, que os melhores autores condemnaram, e conseguiram estirpar da prática abusiva, que a introduzira" JOÃO LUIS ALVES considera como licitação a hasta publica do art. 1777, porém diz: "O Cod. veio, pois, ao encontro dos principios dominantes no Dir. Ant., estabelecendo um caso unico em que é admittida, nas partilhas, a licitação, fóra delle condemnada"

$$
*
$$

(1) - D'alii o chamar-se-lhes lotes ou sortes. 
Ora bem: que pretende a segunda corrente? Simplesmente isto: no direito anterior, bastava que um coherdeiro se oppuzesse á licitação, para que o juiz não a pudesse decretar; a segunda corrente decreta não apenas a licitação entre coherdeiros, mas a hasta publica, quando ha herdeiro que se oppõe á medida! De sorte que os esforços para se abolir a licitação chegariam a este ponto: passar a admittir a licitação com toda a amplitude, admittindo estranhos e sem as restricções que a ella eram feitas no direito anterior! Fugir de um ribeiro e entrar num rio!

Pereira de Carvalho, o. c., nota 170, explica porque não pode o juiz decretar a licitação, oppondo-se um coherdeiro: é "porque resultaria o absurdo de ser esse coherdeiro obrigado a vender a parte que lhe compete na cousa commum, contra expressa disposição da Ord. do Liv. 4. ${ }^{\circ}$, Tit. 11"

Já os nosso praxistas se oppunham ás licitações, para que as legitimas não se assignassem em dinheiro (GuERr. For., Q. 100, n. 6 - apud LoBÃo, Supplem. ás acc. summ., p. 144) e á retalhação dos predios LoBÃo, Notas a Mello, vol. $3 .^{\circ}$, p. 384 ) e recommendavam que se attendesse á commodidade de algum dos coherdeiros em particular, sem offensa da justiça (MICHAL de Frat., p. 3, C. 38, n. $^{\circ} 22$ - apụd LoBÃo, 1. c.)

Aquelles que pugnam pela hasta publica fazem-no com o fim de igualar as legitimas, como declara DiAs FERREIRA, em relação ao Codigo português. Essa razão, porém, não era justificavel nem em nosso dir. ant., de vez que o perigo de adjudicação, por preço vil, não mais poderia existir, visto haver o remedio da Ord., L. $3, \mathrm{~T} 78, \S 2$ e T $17, \S 5$.

E em nosso direito actual, qual o juiz que, em havendo prova de erro ou de dolo, nas avaliações, não mandará proceder á segunda?

Entre as razões de preferencia, Clovis aponta a prioridade, contra a qual se manifestou o sr. Costa MANSo (Revista dos Tribunaes, 51/444) porque "pode provocar uma corrida, tumultando o processo do inventario" 
Não tem razão o douto juiz, pois a prioridade tem de ser posta em face dos outros motivos de preferencia, invocados pelos pretendentes á adjudicação; e bem é de ver que ella apenas valerá, não havendo outro motivo relevante.

Não se pode, outrosim, contestar o valor da prioridade, que é um dos motivos de preferencia na remissão, nas execuções (art. 19 do decr. 9549, de 1886), na qual mais de um executado pode pretender a remissão em seu favor. Esta se faz, até a primeira praça, pelo preço da avaliação (Rev. dos Trib., 7/302), e, entre dois candidatos á remissão, deve ser preferido o que remir o immovel total, e o que chegar em primeiro logar (Rev. dos Trib. 15/79) E a elle se refere Coviello, em seu Manuale di dir civ. italiano, p. 489: verbis "Vi sono però delle norme speciali che si desumano da varie disposizione di legge. Una è quella della prevenzione e delle preoccupazione: cioè l'esercizio d'un diritto compiuto in un tempo anteriore prevale sull'esercizio di altro simigliante diritto che si compia posteriormene (melior est conditio occupantis). Così tra vari creditori dello stesso debitore chi prima riesce a farsi pagare, prevarrà su coloro che si presentano più tardi. Cosi ancora nell'esercizio di diritti civici spettanti sulle cose d'uso publico à membri dell'universitas, la prevenzione determina la preferenza (es. occupazione di pubblici sedili, passaggio per una strada, ecc.)" Parece que tem razão o professor italiano. Em um bond, quem primeiro toma logar tem direito de escolher o banco e a ordem nelle. O facto desse primeiro occupante prejudica e extingue o direito do outro. Prior in tempore potior in jure.

Assim, vige, em nosso direito, e no direito comparado, 0 instituto da adjudicação, que alguns espiritos, sem comprehender o alcance, querem banir do juizo familix erciscundae, procurando encontrar sophismas para negar applicação a um texto do nosso Codigo civil. 
Aquelles praxistas que nos transmittiram o sabio ensinamento de que é necessario o consentimento para que haja licitação, na partilha, si hoje resuscitassem, ficariam boquiabertos, vendo que se procura interpretar o direito por modo que ultrapassa a interpretação dos bolshevistas, de uma fórma que fere tão profundamente o senso juridico e o sentimento da familia, esquecendo-se de que ambos são elementos vitaes de uma nacionalidade.

Em summa .

1) Em geral se distingue o modo de fazer cessar a communhão no juizo communi dividundo e no familix erciscundæ;

2) A adjudicação, sem o consenso unanime, é solução mais juridica do que a venda, em identicas condições;

3) Alguns Codigos prescrevem a licitação, em havendo um herdeiro que a requeira (afastam-se da regra apontada em o n. ${ }^{\circ}$ ), havendo excepção para a pequena propriedade, no direito francês. Outros estabelecem a adjudicação, como regra.

4) A solução do caso, conforme se trata de communhão em predio indivisivel, por titulo singular ou universal, geralmente não apresenta uniformidade no mesmo direito. Assim, no direito francês, a regra é a venda, no ultimo caso; no primeiro, apenas quando nenhum queira ficar com a cousa. No direito argentino, é o inverso: no caso de sucessão a titulo singular, a venda, na a titulo universal, a venda, excepto quando a avaliação não é impugnada e a partilha se faz pelo justo valor. No direito espanhol, parece que a solução é uniforme, procedendo-se á venda sempre que um interessado a reclame.

5) O nosso Codigo fixa, como regra, a hasta publica, si não houver quem pretenda a adjudicação. Ergo, verificada a excepção, não se applica a regra. 


\section{$-374-$}

6) Essa interpretação do art. 1777, decorre:

a) da hermeneutica - na lei não ha palavras superfluas;

b) do dir. ant. da peninsula iberica. Nas Sete Partidas assim é disposto. Os nossos praxistas assim o entenderam.

7) A venda forçada é inconveniente sob o ponto de vista social e juridico. Não acontece o mesmo com a adjudicação, pelo justo valor.

Dr. Lino de Moraes Leme.

(Livre docente de Direito Civil) 